\title{
Using Strengths-Based Approaches to Fulfil Academic Potential in Degree Apprenticeships
}

\author{
Authors: Saville, Kelly-Mae; Birdi, Gurkiran; Hayes, Sarah; Higson, Helen; Eperjesi, Frank
}

\begin{abstract}
Purpose The purpose of this paper is to highlight the positive academic and professional outcomes for students who undertake degree apprenticeships which use strengths-based approaches in their curriculum and assessment. The design and implementation of programmes of work-based study which focus on an individual's inherent talents are a new lens for Higher Education, one that enables institutions to see diverse groups of students fulfil their potential and gain academic qualifications. Strengths-based degree apprenticeships offer an effective way to align the needs of Industry with the ambitions of individuals who wish to gain university level qualifications whilst in the workplace.
\end{abstract}

Design/methodology/approach The research adopted a mixed-methods approach. Semistructured interviews with stakeholders in Industry and Higher Education were undertaken and thematically analysed. Student data was analysed quantitatively for students in the degree apprenticeship programmes which incorporate a strengths-based approach to learning and assessment.

Findings The findings from this study highlight that the degree apprenticeships' strengthsbased curriculum and assessment has spearheaded its success. On average, degree apprentices attain $10 \%$ higher grades than students undertaking the same programme through the traditional degree route. Moreover, the module design and tailored support has contributed to over $91 \%$ of apprentices graduating with a $2: \mathrm{i}$ or above.

Research limitations/implications This research is exploratory in nature, focusing on one university's experiences and outcomes regarding a strengths-based approach curriculum and assessment on degree apprenticeships.

Originality/value The findings describe how the knowledge exchange and culture of the Higher Education sector has shifted, and the university's efforts to make progressive relationships with employers. Moreover, this paper describes the challenges in designing curricula and assessing students based on the strengths and skills required for their employment, rather than university mandated learning outcomes. The findings of this paper could influence a strengths-based framework for the development of degree apprenticeships in the United Kingdom.

Keywords strengths-based approaches, degree apprenticeships, higher education, work-based learning, widening participation

\section{Introduction}

Strengths-based approaches are proposed as a new lens for Higher Education (HE), one that enables institutions to see diverse groups of students fulfil their potential and achieve excellence. Strengths-based assessment (SBA) is the measurement of inherent assets and 
behaviours which are indicative of an individual's potential to thrive and flourish as strengthsbased approaches promote the enhancement of personal characteristics and skills already held by the individual (Graves et al., 2018). Based on research from social work, positive psychology, and the business world, this approach enables identification of the inherent talents students bring with them into the university setting; teaching students to develop and apply their strengths to new and challenging learning tasks. SBA continues to progress within the context of $\mathrm{HE}$ as preliminary research conducted internationally has demonstrated the effectiveness of the strengths-based approach (Schreiner, 2010; Shushok and Hulme, 2006; Stebleton et al., 2012), and research in a variety of settings has emphasized that strengths develop best within a context of supportive relationships (Clifton and Nelson, 1992). This explicit focus on students' inherent talents builds the confidence and motivation necessary for achievement and perseverance in education (Schreiner and Anderson, 2005).

One of the key challenges going forward for Industry and HE, is how to engage in mutually valuable knowledge exchanges for the benefit of the economy, $\mathrm{HE}$, and students. Continuing shifts in the labour market, educational reforms and the impact of unemployment have spearheaded vocational learning into our HE institutions (Lambert, 2016). The Leitch Review emphasised the importance of raising the attainment of the workforce by providing vocational education beyond level 5 (HM Treasury, 2006; Lambert, 2016). This call to action has been repeated in further policies aimed at addressing the skills gap in the labour market (National Apprenticeship Service, 2011; DBIS, 2013, 2016). More recently, the Department for Business, Innovation and Skills (DBIS, 2016) emphasised the benefits of working in collaboration with Industry employers to develop a new generation of apprenticeships with a tailored curriculum focused on employer needs and skill shortages. In regard to bridging those gaps in skills and qualifications, it was identified that one of the most effective environments for employed individuals to learn is in the workplace (Lester and Costley, 2010). One significant factor psychologically in an 'integrated approach to degree programmes is that the workplace becomes a source of academically valid learning, rather than simply a site for gaining experience and applying what has already been learned (Lester, Bravenboer and Webb, 2016: 10). Undertaking a degree apprenticeship is one way to compliment this approach. Institutions create closer links with Industry, and this ensures that HE provision meets employers' needs and the economy's demands (UUK, 2017). HE is an important environment to help learners develop their talents into strengths, which can be defined as 'the ability to provide consistent and near-perfect performance in a given activity' (Buckingham and Clifton, 2005: 20). Furthermore, there is evidence that degree apprenticeships benefit the wider economy, stimulating local growth by attracting students who may not have otherwise gone to university, assisting HE institutions in widening their participation and social mobility aims (UUK, 2017).

The widening participation agenda - the commitment to the inclusion of students from social and economic disadvantaged backgrounds is another area where SBA within the confines of vocational learning flourishes. There is a perception that widening-participation students have more significant gaps or weaknesses upon entering university education (Whiteford et al., 2013). However, strengths-based approaches have the strongest potential to enable students to better manage their weaknesses and become independent learners. Research undertaken in the Netherlands, (Schripsema et al., 2017) found that the implementation of strengths-based approaches provided a first indication into how positive performance is associated to the 
vocational interests and experiences of the applicant. Patterson et al. (2012) reported differences in mean scores between different ethnic groups; gaps between groups are much smaller for SBAs than traditional tests e.g. examinations. In terms of widening participation, this suggests the adverse impact of traditional cognitive assessments on recruitment of applications from black and minority ethnic communities.

Traditional students are commonly expected to follow a pathway whereby they enroll full-time in HE immediately after completing their secondary and post-16 educational qualifications. In contrast, non-traditional students are defined using a variety of criteria such as age at enrolment, socioeconomic status, as well as ethnic and migration background. The structural influences between these groups are usually expected to create a gulf in the attainment possibilities between these two student demographics (Arjomandi et al., 2018). In Germany, where degree apprenticeships are commonplace, non-traditional and traditional students demonstrate that other factors such as migration experiences during formative years impact academic attainment. Their research illustrates that there is one significant interaction effect, namely between the university entrance qualification and migration background (Brändle and Lengfeld, 2017). Consequently, the effect of migration background significantly differs between non-traditional students and traditional students. Non-traditional students with migration background actually improve their grades the most (0.29), but also have the worst starting grades (2.70). Their findings suggest that using SBA to recruit students widens participation in HE. Moreover, it indicates that some minority groups within society make better progress, than their traditional-route entry peers.

\section{Aston University: A Case Study}

Aston University sits within an ethnically diverse cosmopolitan, consequentially the institution attracts a higher population of Asian students in comparison to other United Kingdom Higher Education Institutions (35\% at Aston compared to 8\% nationally) and with it, an overall white minority (36\% at Aston compared to $80 \%$ nationally) (Moores, Birdi and Higson, 2017). Formerly a technical college founded by the employers of Birmingham in 1895, Aston gained University status in 1966. The university is not affiliated with the Russell Group, or the Million+ group. Aston University continues to boast success on its integrated placement year provision and subsequent high rates of graduate employability.

The SBA programme at the university has been running since the 2015/16 academic year within Aston's School of Engineering and Applied Science. The quantitative data regarding the non-SBA pathway relates to a comparative traditional undergraduate degree programme taught within the same School. The aim of this study was to explore the potential of SBAs as a means of widening participation within a university setting. Moreover, to offer some recommendations that would help bridge gaps between Industry and university practices.

\section{Methods}

This study took a mixed-methods approach; interviews were conducted with relevant individuals in Industry and HE. Furthermore, student data was analyzed quantitatively for students in the Aston University degree apprenticeship programmes that incorporate SBA. 
Ethical approval was granted by the Ethics Committee within the Centre for Learning Innovation in Professional Practice department at Aston University.

For the purposes of this study, 'Young' students are those who were aged under 21 on entry to Aston, 'Mature' students are those aged 21 or over on entry to Aston. As the SBA course has only been running since 2015/16, final award data is limited. Therefore, this study is exploratory in nature, considering the primary quantitative data and observations from key stakeholders in the field. The qualitative component to this article explores the observations and experiences of key stakeholders in Aston's degree apprenticeship programmes. The interviews examined the topic of SBA; particularly, how this is implemented within a university setting. The quantitative data in regard to the SBA degree in this article relates to students on one of Aston's degree apprenticeship programmes.

\section{Qualitative Research}

Semi-structured interviews were conducted with employers using the strength-based assessments and official bodies related to apprenticeships at Aston University. Interviews covered topics such approaches adopted by Aston University when using strength-based assessments, the success of strength-based assessments, bridging the gap between Industry and education, and widening participation. The interview schedule was informal to allow for ease of discussion. Interviews were then transcribed and thematically analysed focusing on the topics of SBA, student demographics, curriculum and degree design and finally the relationships and responsibilities of Aston with their Industry partners.

\section{Quantitative data analysis}

Undergraduate student performance (end of year or 'stage average mark') and demographic data were obtained via Aston University's electronic records system for SBA and non-SBA entry students for academic years 2015/16 and 2016/17 following the same student cohorts. The non-SBA sample contained the data of 319 students, the SBA sample comprised 199 records of student information. This investigation focuses analysis on: degree classification, first year average mark, second year average mark, gender, ethnicity, entry tariff, and age.

\section{Measures}

Stage average mark was the dependent variable in all analyses and was expressed as a percentage with $100 \%$ being the maximum mark achievable. Although universities often use a variety of methods to determine a student's degree classification, students can be assured of a first-class degree with a mark of $70 \%$ and above, an upper second-class degree with a mark of $60 \%$ and above and a lower second class degree with a mark of $50 \%$ and above. Students with between 40 and 50\% are awarded a third-class degree and below $40 \%$ a degree is not normally awarded.

Gender was coded as male or female. Ethnicity data were recorded as declared by the students themselves using the 18 categories used for United Kingdom census data, but later grouped into the superordinate categories of 'Asian or Asian British,' 'Black/African/Caribbean/Black British,' 'White,' 'Mixed/Multiple ethnic groups' and 'Other'.

The data were coded and statistically analysed using IBM SPSS version 23. Once coded, ANCOVAs and multiple regression were used to analyse the data. Stage average mark was the 
dependent variable. The main independent variables of interest were gender, ethnicity, age, and location. Entry tariff was used as a covariate in the ANCOVA as a statistical control for its influence.

\section{Informed Consent}

All participants were provided with an information sheet describing the study in sufficient detail for them to make an informed decision about their participation. All participants signed a consent form before taking part in the study.

\section{Withdrawal of Participants}

Participants had the right to withdraw from participation at any time during their participation during the interview and for up to two weeks afterwards, without giving a reason. After this time their data was anonymised and included in the dataset for analysis. This was made clear to the participants at the outset and during the study.

\section{Data Handling and Record Keeping}

In accordance with the Data Protection Act 2018 and the General Data Protection Regulation (GDPR) (EU) 2016/679 throughout the project and in any publications, anonymity and confidentiality are assured. All data is kept separate from ethics forms and all study information is stored by ID number only and kept in a locked filing cabinet or held on a password-protected computer. The length of time data will be stored will be in accordance with University Regulations. Only the research team has access to the data.

\section{Results}

\section{Inferential data analysis}

A step-wise multiple regression was performed with the 2015/16 cohort of students for the degree using SBA for entry and a comparable degree using non-SBA for entry. The dataset for the SBA entry degree consisted of 199 students, and for non-SBA the dataset consisted of 319 students. The predictor variables in this analysis were ethnicity, age, disability, prior qualifications, and gender. The dependent variable was stage average mark for that year.

\section{SBA-Entry Pathway}

Ethnicity significantly predicted performance in these students on the SBA pathway $[\mathrm{F}(1,94)=$ $\left.2129.51, \mathrm{p}<0.05, \mathrm{R}^{2}=0.021\right]$. Even with the addition of age, disability status, prior qualification, and gender, ethnicity still predicted performance $\left[F(1,94)=2129.51, p<0.05, R^{2}=0.011\right]$. The model however, was not significant. To further explore ethnicity on the SBA pathway, a oneway ANOVA was conducted and there were statistically significant differences between White, Asian, and Black students for performance $[\mathrm{F}(2,184)=3.332]$, with White students performing better on average $(\mathrm{M}=59.44, \mathrm{SD}=18.3)$, followed by Asian students $(\mathrm{M}=50.84$, $\mathrm{SD}=23.21)$ and Black students $(\mathrm{M}=48.5, \mathrm{SD}=27.91)$.

Variables analysed in a between subjects ANCOVA investigating effects on stage average marks were: gender (male/female), ethnicity (White/Asian/Black), age (young/mature), disability (disabled/ not disabled), and university entry tariff (covariate). An ANCOVA was 
conducted in order to explore interactions between variables. With regards to the SBA pathway, there were no significant main effects of the variables on performance. There was however, a significant interaction between student ethnicity and gender $[\mathrm{F}(2,22)=4.46, \mathrm{p}<0.05)]$. White females performed poorer than BME females, whereas White males performed better than BME males.

A step-wise multiple regression was performed with the same cohort of students in the following academic year (2016/17). The dataset consisted of 233 students. The predictor variables in this analysis were ethnicity, age, disability, prior qualifications, and gender. The dependent variable was stage average for that year. None of the independent variables significantly predicted performance $(\mathrm{p}>0.05)$. An ANCOVA was also conducted to explore interactions between variables. There was a significant relationship between students age and residence in the West Midlands $[\mathrm{F}(1,22)=7.08, \mathrm{p}<0.05)$. Mature students from the West Midlands performed better than Mature students outside West Midlands, whereas the opposite was true for young students.

\section{Non-SBA Entry Pathway}

When comparing student performance in the non-SBA degree, similar results were found, whereby ethnicity still emerged as a significant predictor, but in addition to this, prior qualifications were also significant in predicting performance. A step-wise multiple regression was performed with the 2015/16 cohort of non-SBA degree students. The dataset consisted of 195 students. The predictor variables in this analysis were ethnicity, age, disability, prior qualifications, and gender. The dependent variable was stage average mark for that year. Ethnicity significantly predicted performance in these students $\left[F(1,189)=6.14, p<0.05, R^{2}=\right.$ 14] when controlling for age, disability status, gender, and prior qualification. Additionally, prior qualification also significantly predicted performance $\left[\mathrm{F}(3,191)=3.827, \mathrm{p}<0.05, \mathrm{R}^{2}=\right.$ 10.4]. To further explore ethnicity and prior qualifications, a one-way ANOVA was conducted and there was a statistically significant difference in performance (stage average marks) between students who had entered the course with A level qualifications $(\mathrm{M}=64.39, \mathrm{SD}=10.6)$ and other qualifications $(\mathrm{M}=59.01, \mathrm{SD}=11.33)$. Students with A level qualifications performed significantly better than those with other qualifications (such as BTEC) $[\mathrm{t}(157.42)=$ $3.37, \mathrm{p}<0.05]$. There were no significant differences between young and mature students, or males and females. There were however statistically significant differences $(F(2,192)=5.91)$ between White, Asian, and Black students for performance. Whites $(\mathrm{M}=65.39, \mathrm{SD}=10.11)$ outperformed Asian $(\mathrm{M}=60.35, \mathrm{SD}=11.25)$ and Black students $(\mathrm{M}=58.32, \mathrm{SD}=12.58)$. Posthoc tests revealed that this difference lay between White and Asian students, and White and Black students.

Unlike with the SBA-degree where the effects of ethnicity on performance decreased in the following year with the same cohort of students, ethnicity significantly predicted performance in the following academic year in the non-SBA degree. A step-wise multiple regression was also performed with the 2016/2017 cohort of students in this degree. The dataset consisted of 230 students. The predictor variables in this analysis were ethnicity, age, disability, prior qualifications, and gender. The dependent variable was stage average for that year. Ethnicity significantly predicted performance in these students $\left[\mathrm{F}(5,224)=5.48, \mathrm{p}<0.05, \mathrm{R}^{2}=14\right]$ when controlling for age, disability status, gender, and prior qualification. Additionally, prior qualification significantly predicted performance when not accounting for ethnicity; it was no 
longer significant when ethnicity was taken in to account. To further explore ethnicity and prior qualifications in this academic year, a one-way ANOVA was conducted and there was statistically significant difference in performance (stage average marks) between students who had entered the course with A level qualifications $(\mathrm{M}=58, \mathrm{SD}=18.93)$ and other qualifications $(\mathrm{M}=53.3, \mathrm{SD}=17.86)$. Students with A level qualifications performed significantly better than those with other qualifications (such as BTEC) [ $\mathrm{t}(363)=2.35, \mathrm{p}<0.05]$. There was no significant difference between young and mature students, or males and females. There was however a statistically significant difference $(\mathrm{F}(2,227)=11.63)$ between White, Asian, and Black students for performance. Whites $(\mathrm{M}=66.79, \mathrm{SD}=9.69)$ outperformed Asian $(\mathrm{M}=60.7$, $\mathrm{SD}=9.94)$ and Black students $(\mathrm{M}=59.41, \mathrm{SD}=9.74)$. Post-hoc tests revealed that this difference lay between White and Asian students, and White and Black students.

\section{Discussion}

Strengths-Based Assessment and Curriculum Design

In recent years, there has been a cultural shift in the HE sector, and a move away from 'traditional' educational pathways (Schreiner, 2010; Shushok and Hulme, 2006; Stebleton et $a l .$, 2012). Leese (2010) argues that with a growing population of non-traditional students entering university, the responsibility of adapting to these needs lay with the institutions; the sector must do more to address the requirements of a diverse range of students. With growing speculation as to the future climate of $\mathrm{HE}$, Aston University has taken progressive steps to ensure it meets the needs of its diverse student population. One such focus has been in creating mutually beneficial alliances with those in Industry. One major reform to come out of these alliances has been how students are assessed pre-entry to Aston. As one lecturer acknowledged:

'We introduced strengths-based assessments in the [degree] programme, in response to, essentially, some understanding of best practice that employers had been developing. Employers have been using strengths-based assessments as part of their recruitment efforts for a number of years. We're working with a company who are specialists in strengths-based recruitment.'

Aston University currently runs eight degree apprenticeship programmes, with a further seven in development. Currently three of these programmes, which in collaboration with employers in related industries, admits applicants on the basis of SBA. As one stakeholder explained:

'Aston have the first degree apprenticeships in the UK [designed this way using SBA], and they are students from [Industry], who did not get the grades. They wouldn't be on the [traditional] degree programme at Aston, the vast majority of them without having come through the degree apprenticeship route [...] Employers understand that grades aren't a predictor for success in degree apprenticeships, but one of the main points of this project is employers get it. But we [universities] need to show how, ideally, academic performance can also be predicted by strengths, not just work-based performance.'

There is increasing evidence to suggest that SBA is a stronger predictor for success in education than traditional qualifications and screening interviews. Research by Schripsema et al. (2017) revealed how the adoption of strength-based approaches offered a more accurate reflection into 
how positive individual performance is related to the occupational interests and personal experiences of the applicant.

Markedly, as one key stakeholder in this research revealed, the focus on existing strengths rather than prior attainment shifts the emphasis of the whole curriculum structure throughout the length of the degree:

'We create a degree apprenticeship, and then everyone has assumed we will assess people in the same way to come on to it, and then we go, "Hang on. Why? We've just written a completely new programme based on very different principles. Why are we [assessing] the same way?" and no one's [in the HE sector] really thought about it, to be honest. So Aston have, and they have changed what they do so ... the whole point of degree apprenticeships is [students] working, so they spend $80 \%$ of their time as an employee, and $20 \%$ of the time off the job, studying or de veloping their skills, so their success is linked to them being successful as an employee.'

Previously, research undertaken by Stebleton et al. (2012) into the Gallup Organization's StrengthsQuest higher education program observed how its integrated curriculum design, was directly responsible for the success of the initiative. Therefore, when considering a strengthsbased approach, a whole-curricula perspective must be adopted to ensure success.

\section{Outcomes: Progression, Retention and Attainment of Students}

During the interviews one stakeholder explained the support package offered to students on Aston's degree apprenticeships. They described how the alliance between the university and the employer is essential to provide a continuity package of support to the students. This individualization, creates buffers and provisions which positively impact student outcomes:

'They have something we've called a "skills coach", who's an individual mentor, who goes out to visit that student in the workplace [...] That person not only supports them in that work-based module but also talks to them about how to manage higher education, how to relate the content that they're learning on the programme to what they're doing in their day-to-day working life.'

Previously, research into Aston's pastoral and academic support policy highlighted that one of the university's key strengths which contributed to student retention was its approach to learning gain and 'a culture of empowerment to continually challenge practice' (Pope, Ladwa and Hayes, 2017: 52). In particular, Aston have developed a strategy of support which has 'integrated curriculum, with teaching that draws on experiences of our students, incorporating teamwork and peer support, flexible placements, vocational courses and work-based learning' (Pope, Ladwa and Hayes, 2017: 52). This wholesome approach which emphasizes the need to recognise student's own experiences and embed them in learning, has spearheaded an effective transition between its traditional degrees, and the newly developed degree apprenticeships. Importantly, recognising individual student strengths beyond standard academic qualifications, as well as offering an integrated package which incorporates workplace support has positively impacted student progression, as one lecturer explained:

'I can talk about progression rates, which are a proxy for retention rates. Progression rates are pretty good, round about $95 \%[\ldots]$ Once they get past the first stage, they've 
finished the professional practice module, so they no longer have that skills coach. Rather than pushing a similar model onto them at that point, because, by then, most of them will have made that adjustment, we instead have knocked in a mentoring model, with a professional mentor who makes time to meet students if they request it.'

Data obtained from Aston's student registry system demonstrates the success of Aston's wholesome approach to student support on the degree apprenticeships. Table 1 below represents student outcomes for an SBA entry degree apprenticeship. The figures show that out of 261 students enrolled on the programme in the academic year 2016/17, only 2 students, or $0.8 \%$ of the population, withdrew from the course due to failing to meet the standard required to progress to the next stage.

2016/17

Progression Status Total No. of \% of Total Programme
Students Population

$\begin{array}{lll}\text { Continue } & 126 & 48.3 \% \\ \text { Progress - Proceed to next stage } & 100 & 38.3 \% \\ \text { Awarded } & 13 & 5.0 \% \\ \text { Withdraw - for non-academic reasons } & 11 & 4.2 \% \\ \text { Fail - Repeat failed modules in next } & 7 & 2.7 \% \\ \text { academic year } & 2 & 0.8 \% \\ \text { On leave of absence } & 2 & 0.8 \% \\ \text { Fail - withdraw } & \mathbf{2 6 1} & \mathbf{1 0 0 . 0 \%} \\ \text { Grand Total } & \end{array}$

Table 1: student outcomes for an SBA entry Degree Apprenticeship

\begin{tabular}{lll}
\hline Progression Status & $\begin{array}{l}\text { Total No. of } \\
\text { Students }\end{array}$ & $\begin{array}{l}\text { of Total Programme } \\
\text { Population }\end{array}$ \\
\hline Continue/ proceed to next stage & 196 & $61.6 \%$ \\
Awarded & 58 & $18.2 \%$ \\
$\begin{array}{l}\text { Fail - Repeat failed modules in next } \\
\text { academic year }\end{array}$ & 36 & $11.3 \%$ \\
$\begin{array}{l}\text { Fail- restart whole stage in next } \\
\text { academic year }\end{array}$ & 2 & $0.6 \%$ \\
$\begin{array}{l}\text { On leave of absence } \\
\text { Fail - withdraw }\end{array}$ & 8 & $2.5 \%$ \\
Grand Total & 18 & $5.7 \%$ \\
\hline
\end{tabular}

Table 2: student outcomes for a comparable degree using non-SBA for entry 
When comparing outcomes for students admitted to Aston's Degree Apprenticeships through SBA, with those who take the traditional degree pathway, one stakeholder revealed that grades were markedly higher from students undertaking their degree through the apprenticeship pathway:

The content is very similar. The results are, maybe, no. Average marks perhaps $10 \%$ higher, pass rates maybe $15 \%, 20 \%$ higher.

Moreover, SBA scores tended to be a predictor for success on the course, as one module lead described:

'With the first couple of cohorts that went through, I compared the strengths test results with the results in that first programme module. There was a pretty good correlation between the level at which people were scoring and the results that they were getting at the end of that [on the degree programme]. There was a fair amount of noise, as well, but I think there was a reasonably clear correlation.'

In another interview this view was also observed by a key stakeholder who had analysed their own figures from SBA entry students admitted through their existing employer:

'They still got a first - the same university regulations, same university rules - so that's the first anecdotal evidence that [pre-entry] grades aren't necessarily the right predictor [for academic success]. They graduated this summer, and over $60 \%$ of them have got a first, and it is assessed the exact same way that a group qualification is in a traditional route.'

Figures obtained from Aston's student registry system for the academic year 2016/17, supports the qualitative component to this article; of the $91 \%$ of students who attained a $2: \mathrm{i}$ or above following the SBA pathway, $63.6 \%$ achieved a first. In contrast, $60 \%$ of students following the non-SBA pathway achieved a $2:$ i or above, with $36.2 \%$ graduating with a first (tables $3 \&$ 4).

\begin{tabular}{lllll}
\hline Award Type & $\begin{array}{l}\text { Award } \\
\text { Classification }\end{array}$ & $\begin{array}{l}\text { Total } \\
\text { Awarded }\end{array}$ & No. $\begin{array}{l}\text { \% Awarded as proportion of } \\
\text { awarded population }\end{array}$ \\
\hline Bachelor & of & 1 & 7 & $63.6 \%$ \\
Science & $2: 1$ & 3 & $27.3 \%$ \\
& $2: 2$ & 1 & $9.1 \%$ \\
\hline
\end{tabular}

Table 3: awarded qualifications for degree using SBA for entry

\begin{tabular}{lllll}
\hline Award Type & $\begin{array}{l}\text { Award } \\
\text { Classification }\end{array}$ & $\begin{array}{l}\text { Total } \\
\text { Awarded }\end{array}$ & $\begin{array}{l}\text { No. } \% \text { Awarded as proportion of } \\
\text { awarded population }\end{array}$ & $\begin{array}{l}\text { of } \\
\text { Bachelor }\end{array}$ \\
of & 1 & 21 & $36.2 \%$ \\
& $2:$ Science & $2: 2$ & 14 & $24.1 \%$ \\
& Below 2:2 & 12 & $20.7 \%$ \\
\end{tabular}

Table 4: awarded qualifications for degree using non-SBA for entry 


\section{Student Demographics}

Aston University is an ethnically diverse organization with a considerable proportion of students coming from Asian backgrounds (35\% vs. circa $8 \%$ nationally), and in addition, 'an overall white minority' with white students accounting for ' $36 \%$ vs. around $80 \%$ nationally' of the student population (Moores, Birdi and Higson, 2017: 3). Moreover, research by Pope, Ladwa and Hayes (2017: 48), which described the socio-economic background of the student population, revealed that ' 42.1 per cent are from the four lowest socio-economic groups against the sector average of 33 per cent'. In terms of students on the SBA entry degree apprenticeships from socially disadvantaged backgrounds, figures are broadly in line with those found in degree programmes which follow the traditional route, as one module convenor explained:

'In terms of access of disadvantaged groups, the proportion of students admitted from, I think, the four most deprived social class backgrounds is at around about $45 \%$, which is above the University's target of $35 \%$.'

Although Aston has successfully managed to ensure that their degree apprenticeships have not created barriers from disadvantaged economic groups, one stakeholder discussed how the problem may be perpetuated nationally:

'The idea of degree apprenticeships is about widening participation, but I think the reason we're not necessarily there, as a UK, as the whole of the country, is because not enough people know about them. So, a lot of parents know about degree apprenticeships because they are working middle-class, and they know that in their organisations apprenticeships are happening, or they read about it in the press.'

With regards to students from BME backgrounds, one module lead stressed that due to the offcampus nature of the course, the ethnic makeup of students on the degree apprenticeships are not as diverse as those undertaking on-campus programmes:

In terms of Aston, I'm not sure that we're going to get with degree apprenticeships the same proportion of ethnicities that we do for our on-campus degrees, because these apprenticeships have a UK-wide reach and because at Aston we draw in a fairly biased way from the Birmingham area, which has a different ethnic make-up to the rest of the country.'

The figures collected during this research demonstrated there was a statistically significant relationship between ethnicity and gender $\left(x^{2}(4)=18.02, p<0.05\right)$ for students enrolled in $2015 / 16$. There is a higher percentage of males in the White student population, but this gender difference decreases with the BME population. This was contrary to the degree using non-SBA for entry whereby there was no significant relationship between gender and ethnicity. 
In terms of widening participation from an Industry perspective, a key stakeholder described the challenge of reflecting the broader society in recruitment via traditional avenues, explaining the benefits SBA:

'One of the challenges facing IT companies is it's really difficult to attract women, and strengths-based recruiting shows no adverse effects on anyone across gender, sociomobility or ethnic diversity.'

This view was reiterated in an interview with a module lead who examined SBA results of incoming students:

'The thing that we were most concerned with was, again, specific to this programme: numerical reasoning. Sometimes, if you don't have a computing A-level, we can use maths as a proxy for that. But, again the same problem was there: maths A-levels. The gender balance there and the focus on less academically focused students, you're excluding again sections of the population.'

During the interviews with stakeholders and module leads, it became apparent that due to the nature of the degree apprenticeships on offer at Aston, some of the qualification and skills deficits, particularly in maths, were being reproduced during the SBA. The module lead felt that this had repercussions on the recruitment of women, and students who were previously not considered 'academically focused'. As another stakeholder acknowledged:

'Computing programmes, of which [degree apprenticeship] is one, don't have a great record for certain types of diversity. For instance, gender balance in computing programmes is fairly poor. The gender ratio now on programme is roughly 80 to 20 male to female, which doesn't sound great, but it's better than elsewhere.'

Figures used during this research showed there was no statistically significant relationship between gender and age $\left[x^{2}(1)=3.04, p>0.05\right]$ when chi-squared tests were conducted with the $2015 / 16$ cohort of students. Interestingly however, there is a higher percentage of males in the 'mature' age group than females, the opposite is true for students in the 'young' age group. This was in contrast to the degree using non-SBA for entry whereby there was no significant relationship between gender and age.

Data obtained from Aston's student registry shows a clear increase in the admittance of women since the start of the programme in 2015 to the current academic year (2017-2018).

\section{Gender}

\begin{tabular}{lllll}
\hline Year & No. Female & \% Female & No. Male & \% Male \\
\hline $\mathbf{2 0 1 5} / \mathbf{1 6}$ & 28 & $14.1 \%$ & 171 & $85.9 \%$ \\
$\mathbf{2 0 1 6 / 1 7}$ & 43 & $16.5 \%$ & 218 & $83.5 \%$ \\
$\mathbf{2 0 1 7 / 1 8}$ & 55 & $18.6 \%$ & 241 & $81.4 \%$ \\
\hline
\end{tabular}

Table 5: distribution by gender by academic year (SBA entry) 


\begin{tabular}{lllll}
\hline Year & No. Female & \% Female & No. Male & \% Male \\
\hline $\mathbf{2 0 1 5} / \mathbf{1 6}$ & 45 & $14.2 \%$ & 273 & $85.8 \%$ \\
$\mathbf{2 0 1 6 / 1 7}$ & 51 & $13.9 \%$ & 315 & $86.1 \%$ \\
$\mathbf{2 0 1 7 / 1 8}$ & 71 & $15 \%$ & 401 & $85 \%$ \\
\hline
\end{tabular}

Table 6: distribution by gender by academic year (non-SBA entry)

In terms of the age of students being admitted to the degree apprenticeship, the figures show an increase in demand across all age groups. However, there is rapid growth among young students, where in the cohort joining in 2017/18 outnumbered the mature students for the first time (SBA entry). This is in contrast to the non-SBA entry, which shows figures are broadly similar during each academic year.

Age on Entry

\begin{tabular}{lllll}
\hline Year & No. Mature & \% Mature & No. Young & \% Young \\
\hline $\mathbf{2 0 1 5} / \mathbf{1 6}$ & 122 & $61.3 \%$ & 77 & $38.7 \%$ \\
$\mathbf{2 0 1 6 / 1 7}$ & 133 & $51.0 \%$ & 128 & $49.0 \%$ \\
$\mathbf{2 0 1 7 / 1 8}$ & 135 & $45.6 \%$ & 161 & $54.4 \%$ \\
\hline
\end{tabular}

Table 7: distribution by age by academic year (SBA entry)

\begin{tabular}{lllll}
\hline Year & No. Mature & \% Mature & No. Young & \% Young \\
\hline $\mathbf{2 0 1 5} / \mathbf{1 6}$ & 26 & $8.2 \%$ & 292 & $91.8 \%$ \\
$\mathbf{2 0 1 6 / 1 7}$ & 22 & $6 \%$ & 344 & $94 \%$ \\
$\mathbf{2 0 1 7 / 1 8}$ & 24 & $5.1 \%$ & 448 & $94.9 \%$ \\
\hline
\end{tabular}

Table 8: distribution by age by academic year (non-SBA entry)

Chi-squared tests showed no significant relationship between ethnicity and age $\left(x^{2}(4)=4.61\right.$, $\mathrm{p}>0.05$ ). However, there was a higher percentage of mature students ( $>21$ years of age) than young students for all ethnic groups. This was similar to the degree using non-SBA for entry whereby there was no significant relationship between gender and age.

\section{Conclusion and Implications}

Our findings describe how the knowledge exchange and culture of the HE sector has shifted, and Aston's efforts to make progressive relationships with employers. These links with Industry benefit itself, the economy, and not least, the wider community. Moreover, this article details one of the challenges Aston had to overcome, in designing curricula and assessing students based on the strengths and skills required for their employment, rather than university mandated learning outcomes. 
Our exploratory investigation examined the academic outcomes of students on the non-SBA pathway with comparative data for the SBA degree apprenticeships. Indeed, the progression and retention rates of students demonstrate that SBA pre-entry students do exceptionally well during their academic studies; giving the first indicator that SBA scores are a predictor for success in HE. Moreover, we detailed the grade classification outcomes for students who graduated from the first cohort completing an SBA entry programme. The data demonstrates that these students, on average, attain 10\% higher grades than students undertaking the same programme through the traditional degree route.

Previously, research into Aston's student demographics revealed that one of the key strengths of the university was its ability to attract applicants from a diverse range of backgrounds, both culturally and economically (Moores, Birdi and Higson, 2017). This research has discovered that although still above the university's own targets, the student demographic in those undertaking degree apprenticeships are not yet as diverse as other programmes offered by Aston. However, the data demonstrates a small but steady increase and levelling within the population which stakeholders are confident can be maintained going forward. This research has revealed that future investigations into this area must focus on the discrepancy between gender and ethnicity with regards to enrolment on degree apprenticeships.

Our findings from this study highlight that the SBA degree apprenticeships' curriculum has played a massive part in its success. The findings demonstrate that module design and tailored support has contributed to over $91 \%$ of apprentices graduating with a 2:i or above. A curriculum which is designed to focus on students' strengths, rather than weaknesses, nurtures an environment where students feel confident going forward through their education. In comparison, figures show that the non-SBA pathway has weaker results from students entering the course with qualifications other than A-levels. Traditional module design, whereby students are evaluated using methods such as written examinations and assessments, may hinder the progress and attainment in students entering the university from non-traditional backgrounds and/or qualifications.

\section{References}

Arjomandi, A., Seufert, J., O’Brien, M., \& Anwar, S. (2018). Active Teaching Strategies and Student Engagement: A Comparison of Traditional and Non-traditional Business Students. EJournal of Business Education and Scholarship Teaching, 12(2), pp. 120-140.

Brändle, T., \& Lengfeld, H. (2017). Drifting apart or converging? Grades among nontraditional and traditional students over the course of their studies: a case study from Germany, Higher Education - DORDRECHT- ELSEVIER PUBLISHING COMPANY THEN KLUWER ACADEMIC PUBLISHERS, 73(2), pp. 227-244.

Buckingham, M., \& Clifton, D. O. (2005). Now, Discover your Strengths: How to Develop your Talents and those of the People you Manage. New York: Pocket Books.

Clifton, D. O., \& Nelson, P. (1992). Soar with your strengths. New York: Dell. 
Graves, S. L., Castro-Olivo, S., \& Nichols, K. (2018). Training in strength-based intervention and assessment methodologies in APA-accredited psychology programs. Psychology in the Schools, (1), pp. 93-100.

Lambert, S. (2016). Are current accountability frameworks appropriate for degree apprenticeships?. Higher Education, Skills and Work-based Learning, 6(4), pp. 345-356.

Leese, M. (2010). Bridging the gap: supporting student transitions into higher education. Journal of further and Higher Education, 34(2), pp. 239-251.

Lester, S., Bravenboer, D., \& Webb, N. (2016) 'Work-integrated degrees: Context, engagement, practice and quality: A literature review for QAA' [Google Scholar]

Lester, S., \& Costley, C. (2010). Work-based learning at higher education level: Value, practice and critique. Studies in Higher Education, 35(5), pp. 561-575.

Moores, E., Birdi, G. K., \& Higson, H. E. (2017). Placement Work Experience May Mitigate Lower Achievement Levels of Black and Asian vs. White Students at University. Frontiers in psychology, 8, pp. 1518.

Patterson, F., Ashworth, V., Zibarras, L., Coan, P., Kerrin, M., \& O’Neill, P. (2012). Evaluations of situational judgement tests to assess non-academic attributes in selection. Medical education, 46(9), pp. 850-868.

Pope, Ladwa and Hayes (2017). 'Improving Retention' in HEPI (eds) Where Next for Widening Participation and Fair Access: New Insights from Leading Thinkers, (p47-54) London: HEPI

Schreiner, L. A. (2010). The "Thriving Quotient" A New Vision for Student Success. About Campus, 15(2), pp. 2-10.

Schreiner, L. A., \& “Chip" Anderson, E. (2005). Strengths-based advising: A new lens for higher education. NACADA Journal, 25(2), pp. 20-29.

Schripsema, N. R., van Trigt, A. M., Borleffs, J. C., \& Cohen-Schotanus, J. (2017). Impact of vocational interests, previous academic experience, gender and age on Situational Judgement Test performance. Advances in Health Sciences Education, 22(2), 521-532.

Shushok Jr, F., \& Hulme, E. (2006). What's right with you: Helping students find and use their personal strengths. About Campus, 11(4), 2-8.

Stebleton, M. J., Soria, K. M., \& Albecker, A. (2012). Integrating strength-based education into a first-year experience curriculum. Journal of College and Character, 13(2).

Whiteford, G., Shah, M., \& Nair, C. (2013). Equity and excellence are not mutually exclusive: A discussion of academic standards in an era of widening participation, Quality Assurance in Education, 21 (3), pp.299-310. 